\title{
Library Jargon: Student Comprehension of Technical Language Used by Librarians
}

\section{Rachael Naismith and Joan Stein}

Jargon, or technical language, appears in both the writing and speech of librarians in their dealings with the public. If the library patron cannot comprehend this language, the reference transaction is impeded. This study measures students' comprehension of a selection of library terms that were derived from actual reference interviews and library handouts. A multiplechoice test was administered to a group of freshmen. "Thinking-aloud" or protocol analyses were also run for information as to the reasoning processes used by the subjects. Given the results of this testing which show that patrons misunderstand library terms approximately half of the time, the researchers offer librarians a continuum of solutions.

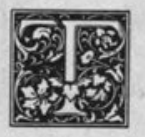

his study examines the issue of jargon in librarianship, including terminology used in the handouts written by librarians and the vocabulary used in conversations with library users, typically in the reference interview. As is true with many professions, librarianship employs many words and phrases that can be considered technical language. Technical language or jargon provides a shorthand means of labeling frequently used concepts. Librarians, in their discussions with peers, cannot redefine common terms over and over again. A label is affixed to a more complex idea, and this label takes on an everyday, understood meaning.

A problem occurs when that label is used to communicate with an audience that is unfamiliar with the specialized use of a term. To a librarian, the word citation may be as familiar as the word coffee. To an undergraduate or even graduate student, this may not be so. Can such language affect reference transactions, in a field in which "user-friendliness" is a common concern?

This study was designed to measure students' comprehension of terms derived from reference interviews and handouts. While "jargon" is not always considered synonymous with "technical language," for the purpose of this study these terms will be used interchangeably.

\section{REVIEW OF THE LITERATURE Communication Models}

A number of communication models have been proposed by researchers. In recent years, cognitive psychologists have adopted models that have added subjective components lacking in earlier models. Figure 1 is a simplified diagram of Terry Winograd's discourse model. ${ }^{1}$

The two participants, the speaker and the hearer (or writer and reader), each possess a set of cognitive structures, or stored schemas, some of which existed before the discourse event. Simply put, a

Rachael Naismith is Publications Coordinator and Reference Librarian and Joan Stein is Head of Resource Sharing at Carnegie Mellon University, Pittsburgh, Pennsylvania 15213-3890. The authors would like to acknowledge the assistance of Professor Tom Huckin for his guidance and knowledgeable suggestions, of the Carnegie Mellon University reference librarians who participated in the study, of the library administrators who supported their research, and of Marilyn Jacobs for assistance with statistical data. 
Speaker's

Hearer's intended meaning

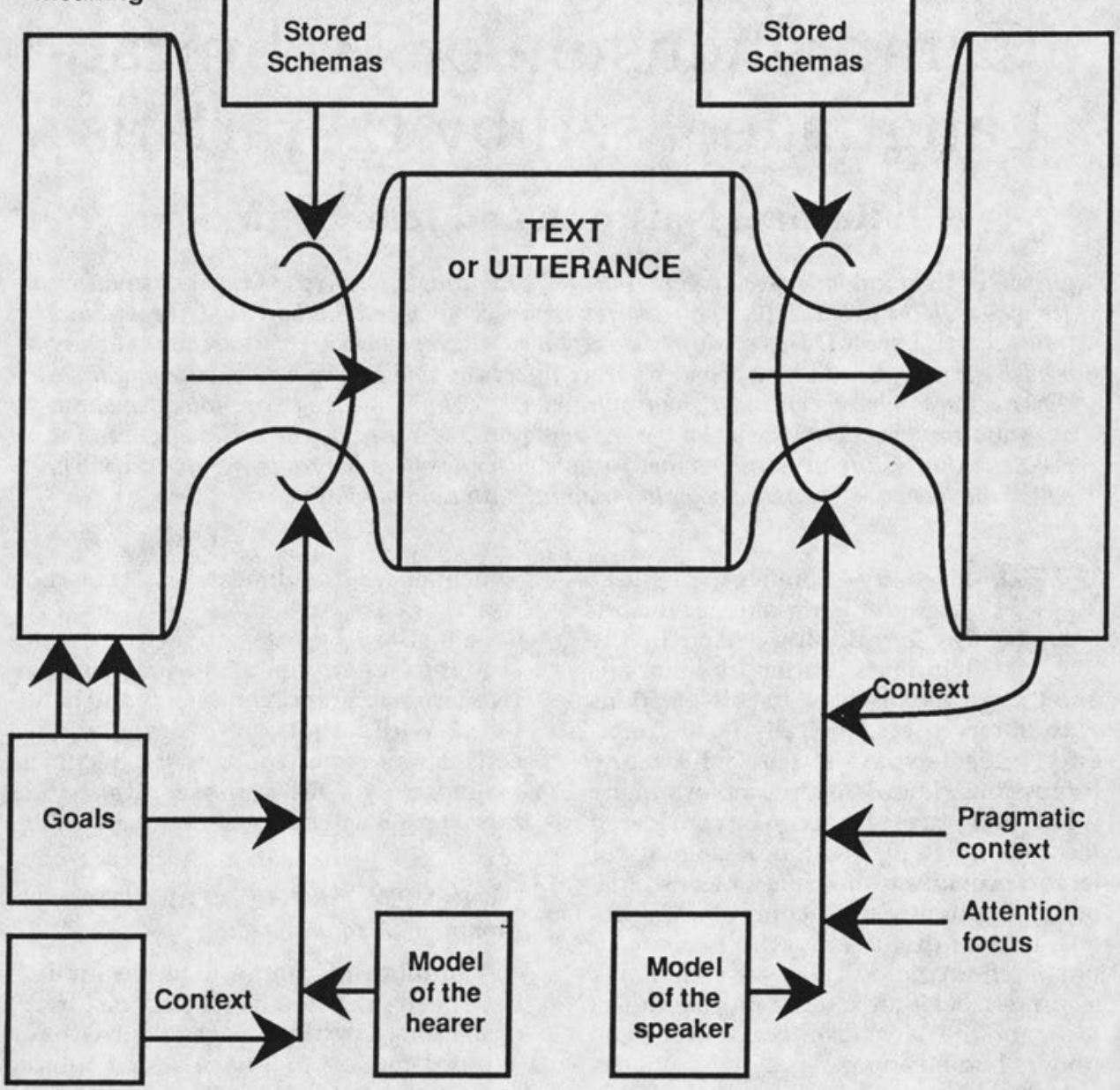

\section{Previous} schemas from this discourse

FIGURE 1

Model of Communication (Winograd)

schema is a collection of knowledge related to a concept or definition. Schemas are used in the reasoning process by which discourse becomes understood. Schemas develop over the course of the transaction through analysis of words chosen, tone used, and so on. The hearer considers the context of the spoken information and compares the data to existing schemas, noting differences between the data and the schematic structures. The hearer may refer to more than one schema in the effort to interpret the data.

In addition, each participant has a 
model of the other person, which develops during the conversation. The processing of the information (written or verbal) involves linguistics at a variety of levels, including syntax, conversational conventions, and word meaning. In this model, "meaning" covers all of the speaker's and hearer's goals. At the most basic level, these goals take the form of the words selected by the speaker. The hearer's comprehension of words is affected by the hearer's model of the relevant "world" and of the speaker.

Related to this model is the idea of attribution. The individual takes cues from the message or situation and judges, based on preexisting schemas, whether the situation is familiar or not. If the content of the situation seems familiar, the hearer follows the earlier path of conclusions. If the situation is not familiar, the individual attributes conclusions through abstract reasoning and inference. According to this model, comprehension is a creative process on the part of the hearer. ${ }^{2}$

\section{Reference Interviews}

Numerous articles have been written about the reference interview. Most of the articles stress that the reference librarian is the intermediary or link between the user and the information system. Articles that have been written about question negotiation tend to focus on the language used by library patrons, as opposed to that used by librarians. Ellis Mount recognized that one obstacle to a successful reference transaction is an inquirer's lack of knowledge of library terminology. This makes it difficult for the library patron to use reference tools and ask understandable questions. ${ }^{3}$

One article examines the use of jargon by reference staff members and users in a medical school library. ${ }^{4}$ Library staff members were asked to record use of "short titles, terms, and abbreviations used by staff and library users to refer to any information source."' The researchers conclude that jargon is used extensively in reference departments, by both staff and users. They state that jargon can be used as an effective communication tool between health professionals, who originate much of the jargon, and librarians. They recommend that library schools teach common jargon to future medical librarians.

Related to discussions about reference interviews are discussions about the language of online searching. The language of computers is now part of the language of libraries. Library users now encounter communication barriers through computer manuals, online help screens, and searching instructions provided by librarians. In one article, Bonnie Snow recommends that professional searchers customize their training methods to accommodate occasional users. She comments that "use of jargon is a habit so ingrained in most professional searchers that detecting it is one of the greatest challenges in designing handouts, visual aids, and other teaching tools." 5

One final aspect of reference interviews that has been discussed in library literature is attitude. Librarians may assume either a vertical or horizontal relationship with library users. In a vertical relationship, an individual nurtures his or her self-concept, maintaining a superior image, with negative results for others. In a horizontal relationship, communication is positive and nonthreatening. The librarian treats the user with respect as an equal. The conversation that flows back and forth is honest, unintimidating, and noncompetitive. ${ }^{6}$

\section{Written Documents}

Style manuals and composition texts have defined standard rules for writing clarity. In recent years, there has been a more detailed examination of reader comprehension related to writing styles. Part of the impetus for this is the "Plain English" movement, an effort to improve the writing of public documents that were previously ambiguous or even incomprehensible to the people who used them. This movement is gaining momentum, with a number of state laws now specifying that functional documents such as insurance policies and leases be written clearly.

Many library documents are functional documents, in that they lead a person through an avenue of library research, 
pinpointing specific sources that must be secured and used. Because functional documents are read for use, not pleasure, they need to be written in an easy-tofollow style. ${ }^{7}$ One principle that many advocates of Plain English feel increases readability is the avoidance of jargon.

"Green warns against using technical terms unnecessarily or inappropriately, confronting the reader with obscure expressions rather than plain words."

In one research study on technical writing, David Green notes that technical terms inevitably develop with the growth of expertise in an area, and they can serve a practical function. "By using the term writers can ensure that readers familiar with its designation will understand them-that is, that they will build an appropriate mental representation. ${ }^{\prime 8}$ Green warns against using technical terms unnecessarily or inappropriately, confronting the reader with obscure expressions rather than plain words.

In an essay on readability, Thomas Huckin stresses that the writer must consider the expertise of the audience. According to the schema theory discussed above, prior knowledge serves as a framework that makes the new information more meaningful and easier to absorb.' Huckin suggests that specialists can easily comprehend standard terminology in a field, even when it is long and difficult. Nonspecialists, on the other hand, need familiar concepts and require definitions, examples, analogies, and other forms of illustration. Unfortunately, as Huckin points out, writing in a way that will be optimally readable for a diverse audience is an extremely difficult task.

Several researchers have discussed the reasons why some authors adopt a tone that might be considered scholarly or aloof. This style of speaking or writing is typically impersonal, full of abstract nouns, passive sentences, and scientific- sounding technical terms. Green studied the efforts of technical writers writing for several levels of audience. He concluded that "individuals who rate their work as scientifically important are more inclined to leave technical terms undefined when they need to be defined." 10

While articles on clear writing are available and helpful to librarians, few articles have been written about library publications per se. ${ }^{11}$ In one, William Jackson states that the tone of library guides is frequently very formal, " in a style that is best understood by other librarians. ${ }^{12} \mathrm{He}$ advises against using words such as "stacks" to describe shelves that contain books. He also suggests that headings not merely be terms such as "Indexes and Abstracts." He points out that many of the readers who know the meaning of these terms already know how to use the reference sources. The title "Indexes and $\mathrm{Ab}$ stracts" may alienate the library novice, discouraging him or her from reading the guide. This is obviously undesirable, since library guides are designed to teach library skills to people who need them. Jackson's preference would be the heading "Finding Journal Articles on a Topic."

This review of the literature, then, indicates concern on the part of writers and English specialists over the clarity of functional documents. Librarians have expressed a similar concern for clarity with regard to the reference interview. The communication models widely accepted within cognitive psychology, including the Winograd model, provide a context in which these issues can be examined.

\section{EXPERIMENTAL METHOD}

This study measured the comprehensibility of a list of jargon words. The list is a sample of frequently used terms culled from publications such as handouts and from reference interviews. While many of these are standard library terms, others are a reflection of the specific environment at Carnegie Mellon University Libraries. That is, some of the terms, such as "library rep," may be unique to CMU, although the concept of a departmental liaison is common to most academic libraries. 
In most libraries new, local terms evolve to describe services or resources.

The first part of this study determined the popularity of specific handouts, on the assumption that vocabulary used in more popular handouts would affect more students. Handouts used in this study were bibliographies on topics such as artificial intelligence, psychology, or business, and guides to resources such as the online catalog.

To measure popularity, each public service point in the Carnegie Mellon University Libraries displayed twenty-five copies of the handouts that would normally be on display, starting at 8:30 a.m. one Monday. Two days later at 8:30 a.m. the remaining handouts were counted and ranked by greatest to least number taken. From these, the ten most popular were used for the next phase of the experiment.

A class of graduate English students concentrating in technical writing was asked to identify words or phrases that they considered to be technical library terms. Aside from their availability, one reason for selecting these students was that they had had some training in editing techniques and had previous experience in identifying jargon.

The first two pages of each handout were used. For the most part, each handout was given to two students, for greater confirmation of the results. The students were asked to circle the words or multiword terms in each sample handout that they considered to be library technical language. From these results, a list of the circled terms was compiled, with a count of the number of times each word was identi- fied. For example, if the term "viewing carrel area" was circled a total of three times, it received a score of three. Then the total number of times each word actually appeared in the total collection of handouts was counted, because many words appeared several times in the handouts. For each word, the number of times a word was identified was divided by the number of times the word actually appeared. The resulting figure, converted to a percentage, represented both degree of identification and frequency. The list could then be ranked from high to low as a means of selecting the most frequent and most identified words. A final list of ten words was derived from the written samples (see Table 1).

Using the earlier example, "viewing carrel area" appeared twice in the collection of samples distributed, once in two separate handouts. Of the four people who encountered this phrase, three identified it as being technical. The percentage $75 \%$ represents the number of times the word was identified, divided by the number of times it appeared.

An equal number of terms were sought from verbal transactions in the reference department. Four Carnegie Mellon reference librarians volunteered for tape recording of their reference interviews. They were not told the nature of the study until afterward. The tapes were transcribed and divided into two-page handouts.

The same procedure was followed for the verbal transcripts as for the written handouts. A final list of ten words was derived from the verbal samples (table 2 ).

TABLE 1

TECHNICAL TERMS DERIVED FROM WRITTEN PUBLICATIONS

\begin{tabular}{lcccc}
\hline \hline Term & Occurrences & $\begin{array}{c}\text { Times Seen } \\
\text { by Subjects }\end{array}$ & $\begin{array}{c}\text { Times Identified } \\
\text { by Subjects }\end{array}$ & $\begin{array}{c}\% \\
\text { (Ident./Times Seen) }\end{array}$ \\
\hline Clearinghouse & 1 & 2 & 2 & 100 \\
Search terms & 1 & 2 & 2 & 100 \\
University archives & 1 & 2 & 2 & 100 \\
Microform & 4 & 7 & 6 & 86 \\
Viewing carrel area & 2 & 4 & 3 & 75 \\
Catalog screen & 1 & 2 & 1 & 50 \\
Nonprint materials & 2 & 2 & 1 & 50 \\
Online database searches & 1 & 2 & 1 & 50 \\
Primary source & 1 & 2 & 1 & 50 \\
Search statement & 1 & 2 & 1 & 50 \\
\hline
\end{tabular}


TABLE 2

TECHNICAL TERMS DERIVED FROM VERBAL TRANSACTIONS

\begin{tabular}{lcccc}
\hline \hline Term & Occurrences & $\begin{array}{c}\text { Times Seen } \\
\text { by Subjects }\end{array}$ & $\begin{array}{c}\text { Times Identified } \\
\text { by Subjects }\end{array}$ & $\begin{array}{c}\% \\
\text { (Ident./Times Seen) }\end{array}$ \\
\hline Library rep & 1 & 2 & 2 & 100 \\
Multi-volume set & 1 & 2 & 2 & 100 \\
Pre-search & 1 & 2 & 2 & 100 \\
Call number & 5 & 6 & 6 & 100 \\
Citation & 1 & 2 & 2 & 100 \\
Command search & 1 & 2 & 2 & 100 \\
Proceedings & 3 & 3 & 2 & 67 \\
Interlibrary loan & 3 & 5 & 3 & 60 \\
Annual report & 1 & 2 & 1 & 50 \\
Bound journals & 1 & 2 & 1 & 50 \\
\hline
\end{tabular}

\section{TESTING}

The ten words from the written list were combined with the words from the verbal list and twenty multiple-choice questions were designed to test comprehension. ${ }^{13}$ Each question consisted of the term followed by four possible definitions, one of which was correct. The 1983 edition of the ALA Glossary of Library and Information Science was used whenever possible as a basis for writing the correct definitions. Incorrect definitions were based on answers supplied by a small sampling of freshman students who were given a list of these terms and asked to define them. In addition the experimenters designed some definitions, creating logical possibilities based on their knowledge of library operations or of the words in a different context.

Subjects were informed that the terms were words or phrases used in the library. They were asked to circle the letter corresponding to the definition closest in meaning to the numbered term.

The subject group for the testing phase consisted of 100 students from freshman English classes at Carnegie Mellon. These students are required to write a research paper. Experience at Carnegie Mellon has shown that these students frequently seek the help of reference librarians and reference handouts.

\section{RESULTS AND ANALYSIS}

The tests were graded, with total number wrong noted. Table 3 shows the results, ranking the terms from least to most understood.
A social sciences statistical package, SPSS-X (release 2.0) was used to analyze the raw data. The package computed the mean and standard deviation for test scores. Also calculated were the mode and median for number of incorrect answers.

Of the total number of questions, 48.7 percent were answered incorrectly. In other words, almost half of the time subjects were not able to identify the correct definition for commonly used library terms. The mean number of incorrect answers, out of the twenty questions, was 10.290. The mode was 9 incorrect, and the median was 10 . The standard deviation

TABLE 3

RANKING OF TERMS

FROM MOST TO LEAST UNDERSTOOD

\begin{tabular}{lc}
\hline \hline Term & Correct Answers \\
\hline Call number & 83 \\
Bound journals & 82 \\
Interlibrary loan & 75 \\
Microform & 74 \\
Search terms & 71 \\
Catalog screen & 68 \\
Online catalog & 68 \\
Search statement & 53 \\
Online database searches & 53 \\
Pre-search & 52 \\
Library rep & 47 \\
Primary source & 45 \\
Viewing carrel area & 45 \\
University archives & 41 \\
Nonprint materials & 40 \\
Clearinghouse & 38 \\
Citation & 35 \\
Command search & 25 \\
Proceedings & 20 \\
Multi-volume set & 11 \\
\hline
\end{tabular}

$\mathrm{N}=100$ subjects. 
was 2.865 . That is, the majority of results fall between 7.43 and 13.16 incorrect, which represents a normal bell curve. A breakdown of test results can be seen in table 4.

\section{TABLE 4}

BREAKDOWN OF TEST RESULTS

\begin{tabular}{lcc}
\hline \hline Term & $\begin{array}{c}\text { Correct } \\
\text { Answers }\end{array}$ & $\begin{array}{c}\text { Incorrect } \\
\text { Answers }\end{array}$ \\
\hline 1. command search & 25 & 75 \\
2. university archives & 42 & 58 \\
3. catalog screen & 68 & 32 \\
4. viewing carrel area & 45 & 55 \\
5. proceedings & 20 & 80 \\
6. search statement & 53 & 47 \\
7. bound journals & 82 & 18 \\
8. online catalog & 68 & 32 \\
9. interlibrary loan & 75 & 25 \\
10. primary source & 45 & 55 \\
11. nonprint materials & 40 & 60 \\
12. online database & & \\
13. searches clearinghouse & 53 & 47 \\
14. pre-search & 37 & 63 \\
15. multi-volume set & 52 & 48 \\
16. microform & 11 & 89 \\
17. citations & 76 & 24 \\
18. search terms & 35 & 65 \\
19. call number & 71 & 29 \\
20. library rep & 83 & 17 \\
\hline
\end{tabular}

$N=100$ subjects.

Number of questions answered incorrectly: Mean: 10.290

Median: 10

Mode: 9

Based on probability theory, one could expect 25 percent of the subjects to get a question right by chance if they had no knowledge of the term. If over 25 percent selected the right answer, they were performing better than chance. Conversely, one could expect 75 percent of the subjects to select a wrong answer by chance, because there are three answers that are incorrect ( 25 percent each).

\section{LINGUISTIC ANALYSIS}

Numerical data alone gave no clue as to the underlying schemas from which the subjects drew their responses. Protocol analysis was used to give an indication of the reasoning processes. This technique involves methods that attempt to determine the mental processes that a person uses to perform a task. In a verbal or thinking-aloud protocol, subjects are asked to perform a task while thinking aloud as they interact with a document. Because subjects are asked to verbalize anything that comes to mind as they work, theirinformation is more complete and accurate than any comments collected after the task is completed. When people experience difficulty in understanding text, their comments often reveal the nature of the difficulty. ${ }^{14}$

In this study, four subjects, all freshmen, were given the multiple-choice test and asked to verbalize their thoughts as they selected answers. Their comments were tape recorded and transcribed. The transcripts then were coded, with phrases of verbalized thoughts assigned a category of reasoning strategy, as represented in the continuum illustrated in figure 2 . The researchers arrived at these categories by looking at each comment individually and by grouping each verbalization into classes.

The results of the protocols showed that the subjects used a variety of methods to deduce an answer. Often they admitted to simply guessing. Frequently they used standard test-taking techniques, such as comparing the specificity of the answers to the question, to make their decision.

At the other end of the spectrum, the subjects sometimes said that they knew the answer. The protocols indicated, for instance, that subjects were familiar with

\begin{tabular}{|c|c|c|c|c|c|c|c|}
\hline 1 & 2 & 3 & 4 & 5 & 6 & 7 & 8 \\
\hline $\begin{array}{l}\text { Guess } \\
\text { answer }\end{array}$ & $\begin{array}{l}\text { Test- } \\
\text { taking } \\
\text { techniques }\end{array}$ & $\begin{array}{l}\text { Determine } \\
\text { what lib. } \\
\text { would do } \\
\text { ("real-world } \\
\text { knowledge") }\end{array}$ & $\begin{array}{l}\text { Know word } \\
\text { in different } \\
\text { context }\end{array}$ & $\begin{array}{l}\text { Morpho- } \\
\text { logical } \\
\text { analysis }\end{array}$ & $\begin{array}{l}\text { Multi- } \\
\text { word } \\
\text { unpacking }\end{array}$ & $\begin{array}{l}\text { Know } \\
\text { broad } \\
\text { category }\end{array}$ & $\begin{array}{l}\text { Know } \\
\text { term }\end{array}$ \\
\hline
\end{tabular}

FIGURE 2

Categories of Reasoning Strategies 
the concept of interlibrary loan. In one protocol a subject stated: "Interlibrary loan . . . yes, I know this . . . there we go, b, 'cause I know, we have it at school . . . obtaining items from another library system through your library."

In this case, the protocols were in keeping with the multiple-choice results, in which 73 people out of 100 answered this question correctly. In the testing, almost all incorrect respondents gave the answer "the ability to check books out in person from a library other than your own." Both the protocols and multiple-choice tests showed that subjects connected "interlibrary loan" with obtaining materials from another library, but many subjects were unclear about the exact procedure.

Aside from subjects knowing or not knowing the answer, subjects used the other techniques pictured in figure 2 to derive their answers. These methods were of particular interest, because they give a realistic profile of how people arrive at a definition when they do not know the term. When people are unfamiliar with a term used by a librarian, they fall back on their previous knowledge, whether of semantics or of the term in another context, to select a likely answer. This related to Winograd's and Huckin's discussions of schema theory mentioned earlier.

Two semantic techniques, morphological analysis and multiword unpacking, were used to break down terms into their component parts to arrive at definitions. The remaining techniques $(3,4$, and 7 in figure 2) were related to previous experience of some sort. In morphological analysis, a word is broken down into segments (prefixes, roots, suffixes). Each segment is defined individually, or, if of foreign origin, translated. The component definitions are reconstituted to arrive at a sum definition of the word as a unit. An example can be seen in this portion of a transcript:

Microform ... (a) a picture enlarged for an overhead projector .... no, micro means small ... (b) a machine that amplifies or records the voice ... hmmm, no ... (c) a generic term for all forms of smaller images or photographic film ... yeah, that's possible, 'cause form is sort of general . . . (d) any library material that is not in paper form ... Yeah, it's probably c, 'cause that ... fits the description of micro and form.

While this subject arrived at the correct answer, some others that used this method did not. For instance, one of the four protocol subjects broke down the term "nonprint materials" into "materials that cannot be printed," presumably since "non," from Latin, has several negative meanings.

"Multiword unpacking" refers to breaking down noun compounds such as "online database searches" or "call number." The issue of how readers interpret compound nouns is complex, because the words in a string of nouns do not always modify each other in the same way. Is a "viewing carrel area" an area for viewing carrels? Or is it an area containing carrels that view, or carrels for viewing? It is even unclear whether "viewing" serves as a verb or an adjective. The reader must define the meaning of each word and then determine the connection between each word and the others, which may indicate a relationship of composition (brick house), user (student handbook), source (bank loan), purpose (calligraphy pen), and so on. One noun phrase can be potentially ambiguous in as many as twelve different ways, although some of the ambiguity is mitigated by practical considerations such as context. ${ }^{16}$

All of this mental unpacking is timeconsuming and may not lead to a correct "translation." However, a person does get more chances to estimate a correct definition, because each word gives a clue as to the term's meaning. An example of this method can be seen in one subject's statement: "Call number. Yes, that is the number ... each book is assigned ... so that you can call it up."

The other method by which subjects used resources at their disposal to figure out the answer was based on context. Some subjects, though unfamiliar with a specific term, seemed to have a sense of its broader category. Answering the question "command search," for example, one subject said, "Something from a computer ... I know it's on a computer." Closely related to this is the technique of 
trying to reason out how a library would actually function ("real-world knowledge"). The same subject continued, "I know it's on a computer, but checking out book on computer. . . no that's not checking it out . . . person at the desk cannot do that." While in this case the subject was wrong about library operations, he created his response by trying to match up his existing computer schema with his library schema.

\section{"... the majority of the subjects, forty-four, defined citation as 'a no- tice of overdue library materials.' "'}

The final method employed by subjects was selection of an answer based on knowledge of the word in a nonlibrary context. Many terms such as "archives," "proceedings" or "clearinghouse" have several meanings outside of the library. In choosing the answer for the term citation, many subjects were confused by another, nonlibrary use of this word. In one of the protocols, a subject verbalized this: "Um, citation is like a ticket or something for speeding." In a nonlibrary context, citation has a negative connotation, usually involving a fine. As one might expect based on Winograd's communication model, subjects took whatever exposure they had had to the term and transferred this knowledge, with incorrect results. This is confirmed by the multiple-choice testing, in which the majority of subjects, forty-four, defined citation as "a notice of overdue library materials."

\section{SUMMARY: PRACTICAL IMPLICATIONS}

Although each profession has its share of jargon, librarianship is such a heavily user-oriented field that any indication of a lack of communication should be given serious attention. The results reported here indicate clearly that there is a communications problem between librarians and patrons. Librarians cannot rely on the patrons to decipher a meaning from the context. Patrons rely on their existing schemas to help them interpret an unfamiliar term. If these schemas are lacking or incorrect, communication will be unsuccessful.

Given that patrons only understand 50 percent of what librarians say or write, what are the options available to library staff members for closing this gap? The following represents a list of options ranging from the least to most accommodating:

- use terms without defining them, and let the patron sink or swim

- use terms without defining them but be alert to verbal and nonverbal cues from the patron indicating confusion

- solicit feedback from the user as you go along, asking, for instance, "Interlibrary loan-do you know what that is?"

- use visual aids to assist the patron, such as pointing to the components of a citation

- define terms the first time they are used in an interaction or publication, and then use them subsequently without definition

- use formal library instruction to teach library technical language

- append glossaries of terms to written publications

- avoid local terms not useful for patrons' future needs

- define technical terms whenever you use them

- avoid jargon altogether

Neither end of the continuum is ideal. On the one hand, patrons would be poorly served by totally ignoring their need for the definition of these terms. On the other hand, it is impractical, timeconsuming, and unnecessary to define terms every time they are used.

The options between the extremes seem most reasonable and helpful. The best method to select will depend upon the personalities of both the librarian and the individual patron. Often a combination of methods will be effective, whereas one alone might be insufficient. For instance, if a librarian relies on his or her ability to distinguish confusion, verbally or nonverbally, there is a chance that subtle cues may be missed. However, if the librarian is also giving a visual demonstration, on 
the online catalog, for instance, missed communication is less likely.

While this study offers new information regarding comprehension of library jargon, there are many other avenues for further research. Not studied was the actual amount of technical language used by librarians in proportion to other language. Of further interest would be a comparison of terms identified as jargon by librarians as opposed to patrons. Other tests could also be done to extend the research on patron comprehension. It is possible, for instance, that patrons perform better in real- life situations where terms are presented in context. Mock situations could be constructed that are more realistic, or actual transactions could be monitored. It would also be interesting to see how comprehension of technical language might change as one's education progresses. A similar study would be a before-and-after testing with regard to library instruction. It would also be useful to explore the possibility of enhancing library instruction to increase patrons' abilities to interpret and use the many library terms that they obviously do not, at present, comprehend.

\section{REFERENCES AND NOTES}

1. Terry Winograd, "A Framework for Understanding Discourse," in Cognitive Processes in Comprehension, ed. Marcel Adam Just and Patricia A. Carpenter (Hillsdale: Erlbaum, 1977), p.63-88.

2. Saul M. Kassin and Joan B. Pryor, "The Development of Attribution Processes," in The Development of Social Cognition, ed. John B. Pryor and Jeanne D. Day (New York: Springer-Verlag, 1985), p.3-34.

3. Ellis Mount, "Communication Barriers and the Reference Question," Special Libraries 57:575-78 (Oct. 1966).

4. Ruth E. Fenske, "The Use of Jargon in Medical School Libraries," Bulletin of the Medical Library Association 74:12-15 (Jan. 1986).

5. Bonnie Snow, "What Jargon Is Really Necessary When Teaching (And Learning) Online Skills?" Online 10:100-107 (July 1986).

6. Nathan M. Smith and Stephen D. Fitt, "Vertical-Horizontal Relationships: Their Application for Librarians," Special Libraries 66:528-31 (Nov. 1975).

7. Linda Flower, Revising Functional Documents: The Scenario Principle, Communications Design Center Technical Report no.10 (Pittsburgh: Carnegie Mellon University, 1980), p.7.

8. David W. Green, "Writing, Jargon, and Research," Written Communication 3:364-81 (July 1986).

9. Thomas N. Huckin, "A Cognitive Approach to Readability," in New Essays in Technical and Scientific Communications: Research, Theory, Practice, ed. Paul V. Anderson, R. John Brockmann, and Carolyn R. Miller (Farmingdale, N.Y.: Baywood Pub. Co., 1983), p.92.

10. Green, "Writing," p.371.

11. Rachael Naismith, "Establishing a Library Publications Program," College \& Research Libraries News 2:59-60+ (Feb. 1985).

12. William J. Jackson, "The User-Friendly Library Guide," College \& Research Libraries News 45:468-71 (Oct. 1984).

13. For a copy of the graded test, write to either of the authors at Carnegie Mellon University Libraries, Frew Street, Pittsburgh, Pa. 15213.

14. Karen A. Schriver, Plain Language for Expert or Lay Audiences: Designing Text Using Protocol-Aided Revision, Communications Design Center Technical Report no.43 (Pittsburgh: Carnegie Mellon University, 1987), p.10.

15. The actual question, with number of responses, read:

Interlibrary loan:

(a) book purchase funds shared by more than one library - 2

(b) obtaining items from another library system through your library - 75

(c) the ability to check books out in person from a library other than your own - 15

(d) obtaining books or photocopies from other campus libraries - 8

16. Pamela Downing, "On the Creation and Use of English Compound Nouns," Language 53:810-41 (Dec. 1977). 